\title{
CLINICAL APPLICATIONS OF COOMASSIE BLUE
}

\author{
BY \\ S. H. TAYLOR* AND J. P. SHILLINGFORD \\ From the Department of Medicine, Postgraduate Medical School of London \\ Received November 29, 1958
}

Until recently Evans Blue ( $\mathrm{T}-1824)$ was the dye that had been used most extensively in indicator dilution studies and found to possess the desired characteristics of relative non-toxicity and confinement to the intravascular space. However, the use of this dye imposes certain limitations, the chief being that the total dosage of dye administered must be kept small, due to the blue coloration imparted to the skin of the patient and the toxic effects of large doses. Because of these limitations of Evans Blue, several other dyes have recently been proposed as suitable for indicator dilution studies. Among these are Indigo Carmine (Lacy et al., 1955), Bromsulphalein (Wassen, 1956; Mellette et al., 1958), the tricarbrocyanine dyes, "Cardio green" (Fox et al., 1957) and "Rie 1743" (Kramer and Ziegenrücker, 1957), and the blue triphenylmethane dyes (Davis et al., 1958). These dyes are, however, rapidly removed from the circulation by extravascular diffusion and rapid hepatic clearance. This seriously compromises the standardization of the response of an ear oximeter, for direct arterial standardization at the time of the inscription of the curve is essential for quantitative analysis. Coomassie Blue was developed largely in an effort to overcome these difficulties and the purpose of this work was to assess the value of the dye in clinical practice.

\section{METHODS}

Following extensive animal trials, the harmlessness of the dye was established by cautiously increasing intravenous administration in ourselves and later in patients whose condition justified dye studies. The dye was given in amounts ranging from 20 to $1000 \mathrm{mg}$. per injection to a maximum total dosage in one subject of $2000 \mathrm{mg}$. Subjective effects, together with any changes in pulse rate or blood pressure, were noted subsequent to the injection in all patients.

To determine in vitro colorimetric decay of the dye, samples of blood were taken five minutes after its intravenous injection. After centrifuging, the plasma was stored in two fractions, one at room temperature and one at $0^{\circ} \mathrm{C}$. The dye was extracted from the plasma at $1,2,3,4,8,12$, and 24 hours after withdrawal.

The rate of in vivo colorimetric degradation of the dye was studied in the plasma at intravenous dose levels of $25,50,75$, and $100 \mathrm{mg}$. Six patients were studied at each level of dosage and blood samples were taken for extraction and estimation of the dye at $5,10,20,30,40,60,90,120,180$, and 240 minutes after injection.

Loss of the dye from the circulation was studied by measuring the pulmonary clearance (pulmonary arterial-brachial arterial difference), the hepatic clearance (brachial arterial-hepatic venous difference) and arm clearance (brachial arterial-axillary venous difference). Synchronous samples for extraction were taken from the respective vessels at various plasma levels of the dye. In those patients to whom the dye was given in large amounts, urine was collected fractionally during the succeeding 24 hours and extracted to measure the renal excretion of the unchanged dye and its metabolic breakdown products.

* Medical Research Council Fellow in Clinical Research. 
The method of extraction of the dye is as follows: $10 \mathrm{ml}$. samples of blood are withdrawn into tubes, each containing a small amount of powdered heparin, and centrifuged at 3000 r.p.m. for 10 minutes. $1 \mathrm{ml}$. of plasma is extracted by the successive addition of $2 \mathrm{ml}$. saturated urea solution, $4 \mathrm{ml}$. pure acetone, $0.5 \mathrm{ml}$. 10 per cent zinc sulphate, and $0.5 \mathrm{ml} .0 .5 \mathrm{~N}$. sodium hydroxide, the latter two reagents having been standardized by titration against each other to a phenolphthalein endpoint. After shaking thoroughly between each addition of reagent, the tubes are centrifuged for 10 minutes at 3000 r.p.m. The supernatant fluid is transferred by means of a Pasteur pipette from beneath the surface layer of lipids to a second dry tube and centrifuged for a further 10 minutes at the same speed. The optical density of the final supernatant extract is measured spectrophotometrically against suitable blanks prepared from the untreated plasma and a reagent blank in which water is substituted for the plasma. The percentage extraction of the dye is determined by the preparation of two solutions, one, untreated plasma to which a solution of dye is added to give a final concentration of 10 or $20 \mathrm{mg}$., and the other in which water is substituted for plasma. $1 \mathrm{ml}$. of each of these two solutions is then extracted as described, the differences in optical density of the final supernatants being the percentage extraction. Dilutions of the dye in water, for direct reference standards, are prepared from the same batch of dye as used for injection, to eliminate any slight variations in concentration and optical absorption that may exist between different batches of the dye. The spectrophotometer used to measure the optical density in the present experiments was a Unicam S.P. 600 using a filter of $600 \mathrm{~m} \mu$ wave-length.

Fifty-three determinations of the cardiac output were made on 26 patients with rheumatic heart disease, thyrotoxicosis, or essential hypertension. All patients were studied at rest with mild sedation. Simultaneous measurements of the cardiac output were made by the direct Fick method and by the ear-oximeter method of recording dye dilution curves as used by Korner and Shillingford (1955). The ear oximeter was based on the design of Wood and Geraci (1949). The electrical output from the red and infra-red cells was balanced by a potentiometer so that the output from the red cell was normally slightly greater than that from the infra-red cell. The passage of contrasting blue dye through the ear caused a reduction in the current output from the red cell, which was recorded by a direct current chopper amplifier and direct writing recorder. The sensitivity of the amplifier was arranged to give a maximum deflection of 5 to $7 \mathrm{~cm}$. at the peak of a normal dilution curve. The linearity and base-line stability were within 3 per cent of a full-scale deflection up to concentrations of dye of $30 \mathrm{mg}$. To maintain a constant arterial blood oxygen saturation, patients breathed a high concentration of oxygen from a closed spirometer for five minutes before and during the recording of the dye dilution curve. A known amount of either a 1 per cent or 2 per cent solution of Coomassie Blue was injected through a cardiac catheter into the pulmonary artery with a calibrated syringe. The amount of dye injected varied from $15-30 \mathrm{mg}$. and two or three synchronous determinations of cardiac output by the two methods were made. The ear dye concentration was recorded continuously after the injection for three minutes, at which time brachial arterial or antebrachial venous samples were taken. Hæmatocrit determinations were made on these samples and the dye extracted as previously described. The oxygen uptake was determined from the closed oxygen-filled spirometer during the recording of the dye curve. Immediately before injection of the dye into the catheter, samples of mixed venous blood were taken from the pulmonary artery at the same time as brachial arterial samples from an indwelling arterial needle. The blood oxygen content was estimated by a modification of the Haldane method and checked by a modification of Gatman's spectrophotometric method (Wade et al., 1953).

Repeatability of the cardiac output determinations by the dye was tested by carrying out up to five estimations at intervals of approximately five minutes in similar patients. 20 to $30 \mathrm{mg}$. of a 1 per cent or 2 per cent solution of the dye was injected into a peripheral vein and the dye dilution curve recorded from the ear oximeter. The patient breathed a high concentration of oxygen from a plastic face mask for five minutes before and during the determination. The ear dye concentration was recorded continuously until blood samples for calibration of the dye curve were taken, 3 to 4 minutes after the completion of the curve. These samples were used as a plasma dye 
concentration base-line for the succeeding curve, which was executed at the completion of the sample.

More than 40 patients with congenital heart disease were studied. Their ages ranged from 3 to 40 years and they included patients with patent ductus arteriosus, atrial septal defect, ventricular septal defect, anomalous pulmonary venous drainage, Fallot's tetralogy, Eisenmenger's complex, Ebstein's anomaly, and transposition of the great vessels: many were severely cyanosed. Injections of Coomassie Blue (4\%), ranging from 40 to $150 \mathrm{mg}$., were given by selective intracardiac injection. Peripheral vein injections at the same dose range were utilized as an initial screening test in suspected cases of intracardiac shunts. The dye dilution curves were inscribed by the same ear oximeter, but the sensitivity of the amplification system was reduced to counteract the effect of rapidly fluctuating changes in arterial oxygen saturation due both to the shunts and respiration. The reduced sensitivity of the amplifier allowed a steady base-line to be maintained in spite of the fact that many of the younger patients were anæsthetized during the investigations. With this technique it was found that breathing oxygen during the inscription of the curve was unnecessary and all anæsthetized patients breathed room air.

\section{RESULTS}

Toxicity. Confirming the previous findings from animal experiments, no toxic reactions or sideeffects were encountered in any of the 30 subjects initially studied, to whom large doses of the dye had been given, nor in any of the subsequent 90 patients to whom the dye has been given. None of the patients experienced any subjective effects following the intravenous injection of the dye, and heart rate and blood pressure remained completely unchanged. After the intravenous administration of $200 \mathrm{mg}$. to adult patients the resulting slight blue discoloration of the skin disappeared within about one or two hours. With larger doses in adults and similar doses per $\mathrm{kg}$. body weight in children, a blue discoloration of the skin was produced that disappeared within six hours in all patients.

In Vitro Decay of the Dye. There was no detectable colorimetric difference in extracts of the dye at intervals of up to 24 hours. Storage temperature in the range 0 to $20^{\circ} \mathrm{C}$. similarly had no appreciable effect on the percentage extraction of the dye over a period of 24 hours.

Dosage and in Vivo Plasma Decay Curves. The rate of disappearance of the dye from the plasma, following injections of $25 \mathrm{mg}$., $50 \mathrm{mg}$., $75 \mathrm{mg}$., and $100 \mathrm{mg}$., was measured in six patients at each level of dosage and a representative example of each colorimetric decay curve is illustrated in Fig. 1. The rate of disappearance of the dye from the plasma follows a complex pattern involving at least two exponential functions. This suggests that several processes are probably involved in the colorimetric degradation of the dye and this is at present under further investigation.

Quantitative determinations of cardiac output are usually carried out in the dose range of 15 to $30 \mathrm{mg}$. per injection. The decay curve is comparatively steep initially and at this dose range the fall-off due to colorimetric decay of the dye is approximately $0.1 \mathrm{mg}$. $1 . / \mathrm{min}$. However, with calibration samples taken three minutes after injection of the dye the error introduced into the determination is only of the order of 5 per cent. With larger doses of the dye the initial slope of the colorimetric decay curve becomes progressively steeper, increasing the error introduced into the estimations if the direct determinations of plasma level are used. Extrapolation of the semilogarithmic curve to zero time, from further determinations of the plasma dye concentration, are essential in these circumstances to obtain an accurate estimate of the plasma level at the time required.

Tissue Clearance. The simultaneous estimation of the concentration of dye in the pulmonary and brachial arteries was identical in six patients in whom it was measured. Simultaneous determinations were also made of brachial arterial and axillary venous concentrations in twelve patients and were similarly identical. In three patients, one of whom had frank cirrhosis of liver, simultaneous measurement of the concentration of dye in hepatic vein and brachial artery blood revealed no significant difference. These results indicate that the dye does not diffuse in appreciable amounts 
into the tissues of the lung, liver, skin, or muscle at a rate that can be detected by these methods.

Excretion. In no patient was urinary excretion of the unchanged dye detected in the 24 hours following intravenous injection. It is of interest that the vomit of patients following recovery from an anæsthetic, during which the dye had been given, contained a relatively high concentration of dye. It has since been established by animal experiments that the dye is quantitatively excreted in the bile (Thorp, J. M., unpublished observations).

\section{Cardiac Output Determination by Dye Dilution and Direct Fick Technique}

The values for the cardiac outputs determined simultaneously by the dye dilution and direct Fick methods are shown in Table I. Fifty-three comparisons were made in 26 patients at rest and a graphic correlation of these values is presented in Fig. 2. The observations (Table I) marked with

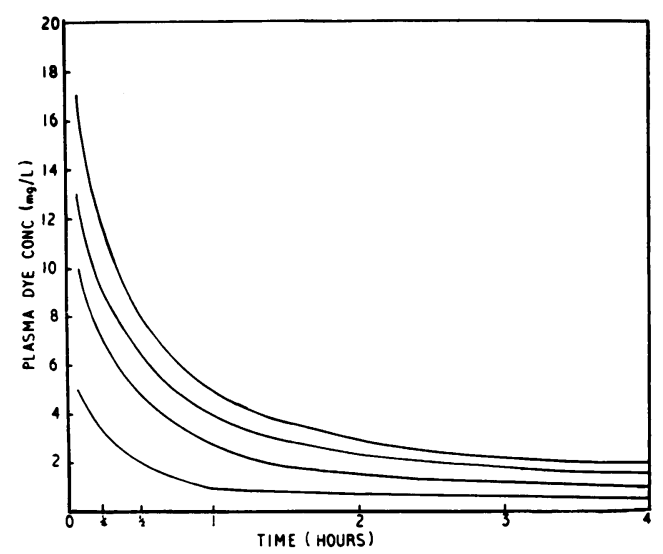

FIG. 1.-Representative curves of the in vivo colorimetric decay of the dye in plasma following intravenous injection of $100,75,50$, and $25 \mathrm{mg}$.

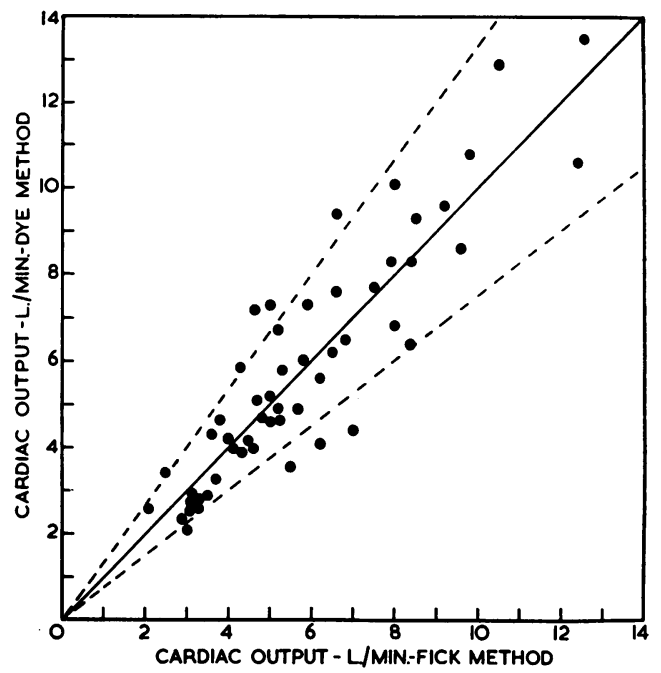

FIG. 2.-Comparison of 53 determinations of the cardiac output in 26 patients by dye oximeter and direct Fick methods.

an asterisk were excluded from the statistical analysis, due to the abnormally large differences between dye determinations in replicate observations, one of which exceeded three times the S.D. of differences. In retrospect this was probably due to errors in the transcription of the dye curve. The mean cardiac outputs for the Fick and dye methods were $5 \cdot 71 \pm 0.331 . / \mathrm{min}$. (S.D. $=2 \cdot 37$ ) and $5.72 \pm 0.361 . / \mathrm{min}$. (S.D. $=2 \cdot 58$ ) respectively. The standard error of the difference between the mean values was $0 \cdot 11 \mathrm{l} . / \mathrm{min}$. and the variance ratio $(\mathrm{D} / \mathrm{F})$ was $1 \cdot 18$. The coefficient of correlation $(0.95)$ and the regression coefficient $(1.04)$ were both close to unity.

These findings demonstrate an approximately equal scatter of values about the line of identity and the absence of any systematic difference between the values obtained from the two methods. Of the 53 comparisons made between the dye and Fick techniques, in all but $12(23 \%)$ the dye method gave values within 25 per cent of the determinations by the direct Fick method. The total scatter of values by the dye method was between +38 and -57 per cent of those determined by the Fick method. These values are similar to those reported by other workers (Hamilton et al., 1948; Werkö et al., 1949; Kopelman and Lee, 1951; Eliasch, 1952; Ohmori et al., 1952; Doyle et al., 1953; Neely et al., 1954; Korner and Shillingford, 1955; and Sekelj et al., 1958).

Repeatability of Estimations. The cardiac output was repeated in 46 instances in 20 patients by the Fick and dye oximeter methods (Table I). The standard deviation of a single observation of the Fick and dye methods was $0.591 . / \mathrm{min}$. and $0.711 . / \mathrm{min}$ respectively. The dye estimations were 
TABLE I

Comparison of Cardiac Output Determinations by Dye Oximeter and Direct Fick Methods in 26 Patients

\begin{tabular}{|c|c|c|c|c|c|c|c|}
\hline Fick & Dye & Fick & Dye & Fick & Dye & Fick & Dye \\
\hline $4 \cdot 0$ & $4 \cdot 1$ & \multirow{2}{*}{$\begin{array}{l}5 \cdot 2 \\
4 \cdot 3 \\
\end{array}$} & \multirow{2}{*}{$\begin{array}{l}6.7 \\
5.8 \\
\end{array}$} & \multirow{2}{*}{$\begin{array}{l}4 \cdot 3 \\
4 \cdot 6 \\
\end{array}$} & $\begin{array}{l}3 \cdot 9 \\
4 \cdot 0\end{array}$ & \multirow{2}{*}{$\begin{array}{c}8 \cdot 0 \\
9 \cdot 6 \\
10.5^{*}\end{array}$} & \multirow{2}{*}{$\begin{array}{c}10 \cdot 1 \\
8 \cdot 6 \\
12 \cdot 9^{*}\end{array}$} \\
\hline $12 \cdot 4$ & $10 \cdot 6$ & & & & & & \\
\hline 2.5 & $3 \cdot 4$ & $\begin{array}{l}8 \cdot 0 \\
7 \cdot 0\end{array}$ & $\begin{array}{l}6 \cdot 8 \\
4 \cdot 4\end{array}$ & $\begin{array}{l}3 \cdot 8 \\
3.6 \\
\end{array}$ & $\begin{array}{l}4 \cdot 6 \\
4 \cdot 3 \\
\end{array}$ & \multirow{2}{*}{$\begin{array}{l}5 \cdot 3 \\
5 \cdot 0 \\
5 \cdot 2\end{array}$} & \multirow{2}{*}{$\begin{array}{l}5 \cdot 8 \\
4.5 \\
4.9\end{array}$} \\
\hline $8 \cdot 4$ & $6 \cdot 4$ & \multirow{2}{*}{$\begin{array}{l}6.6 \\
6.6\end{array}$} & \multirow{2}{*}{$\begin{array}{l}9 \cdot 4 \\
7 \cdot 6 \\
\end{array}$} & \multirow{2}{*}{$\begin{array}{l}2 \cdot 9 \\
3 \cdot 1 \\
\end{array}$} & \multirow{2}{*}{$\begin{array}{l}2 \cdot 4 \\
2 \cdot 7 \\
\end{array}$} & & \\
\hline $6 \cdot 2$ & $5 \cdot 6$ & & & & & \multirow{3}{*}{$\begin{array}{r}3 \cdot 0 \\
3 \cdot 1 \\
3 \cdot 7 \\
3 \cdot 5 \\
\end{array}$} & \multirow{3}{*}{$\begin{array}{l}2.1 \\
2.7 \\
3.3 \\
2.9\end{array}$} \\
\hline $2 \cdot 1$ & $2 \cdot 7$ & $\begin{array}{l}4 \cdot 6 \\
5 \cdot 8\end{array}$ & $\begin{array}{l}7 \cdot 2 \\
6 \cdot 0\end{array}$ & $\begin{array}{l}3 \cdot 1 \\
3 \cdot 2\end{array}$ & $\begin{array}{l}2 \cdot 9 \\
2 \cdot 6\end{array}$ & & \\
\hline \multirow{2}{*}{$\begin{array}{l}7.9 \\
7.5\end{array}$} & \multirow{2}{*}{$\begin{array}{l}8 \cdot 3 \\
7 \cdot 7 \\
\end{array}$} & \multirow{2}{*}{$\begin{array}{l}6 \cdot 5 \\
6 \cdot 8\end{array}$} & \multirow{2}{*}{$\begin{array}{l}6 \cdot 2 \\
6 \cdot 5\end{array}$} & \multirow{3}{*}{$\begin{array}{l}4 \cdot 7 \\
5 \cdot 0 \\
5 \cdot 7 \\
\end{array}$} & $2 \cdot 6$ & & \\
\hline & & & & & \multirow{2}{*}{$\begin{array}{l}5 \cdot 1 \\
5 \cdot 2 \\
4 \cdot 9\end{array}$} & & \\
\hline \multirow{2}{*}{$\begin{array}{l}4 \cdot 8 \\
5 \cdot 2 \\
\end{array}$} & \multirow{2}{*}{$\begin{array}{l}4 \cdot 7 \\
4 \cdot 6 \\
\end{array}$} & \multirow[t]{2}{*}{$\begin{array}{l}5 \cdot 2 \\
4 \cdot 4\end{array}$} & \multirow{2}{*}{$\begin{array}{l}4 \cdot 6 \\
4 \cdot 3\end{array}$} & & & & \\
\hline & & & & \multirow{2}{*}{$\begin{array}{l}8 \cdot 4 \\
8 \cdot 5 \\
9 \cdot 3\end{array}$} & \multirow{2}{*}{$\begin{array}{l}8 \cdot 3 \\
9 \cdot 3 \\
9 \cdot 6\end{array}$} & & \\
\hline $\begin{array}{r}9 \cdot 8 \\
12 \cdot 6\end{array}$ & $\begin{array}{l}10 \cdot 8 \\
13 \cdot 5\end{array}$ & $\begin{array}{l}5 \cdot 6 \\
6 \cdot 2\end{array}$ & $\begin{array}{l}3 \cdot 5 \\
4 \cdot 1\end{array}$ & & & & \\
\hline \multirow[t]{3}{*}{$\begin{array}{l}5.0 \\
5.9 \\
\end{array}$} & $\begin{array}{l}7 \cdot 3 \\
7 \cdot 3\end{array}$ & & & 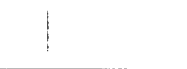 & & 1 & \\
\hline & \multirow{2}{*}{\multicolumn{2}{|c|}{$\begin{array}{l}\text { Fick }(1 . / \min .) \\
\text { Dye }(1 . / \mathrm{min} .)\end{array}$}} & Mean & S.E. of Mean & S.D. 1 & S.D. ${ }^{2}$ & \\
\hline & & & $\begin{array}{l}5 \cdot 71 \\
5 \cdot 72\end{array}$ & $\begin{array}{l}0 \cdot 33 \\
0.36\end{array}$ & $\begin{array}{l}2 \cdot 37 \\
2 \cdot 58\end{array}$ & $\begin{array}{l}0.59 \\
0.71\end{array}$ & \\
\hline
\end{tabular}

S.D. 1 - Standard deviation of all observations.

S.D. ${ }^{2}$-Standard deviation of a single observation calculated from the data in which two or more observations were made in individual patients.

* Observations marked with an asterisk were excluded from the statistical analysis (see text).

carried out by intracardiac injections. The results of successive estimations of the cardiac output by the ear oximeter method, utilizing peripheral vein injections, are shown in Table II. From one to five determinations of output were made in 34 patients. The analysis of variance of five successive cardiac outputs in five patients are shown in Table III. The standard deviation of a single observation for the whole group is 0.621 ./min. which is not significantly different from that calculated for dye outputs by intracardiac injections $(0.711 . / \mathrm{min}$.). Of the 34 duplicate estimates made, 7 $(21 \%)$ are more than 15 per cent without, $2(6 \%)$ are more than 20 per cent without, but all are within 25 per cent of the line of identity.

Of the 19 determinations between the first and third cardiac outputs, four $(21 \%)$ are more than 15 per cent from the line of identity but none are more than 20 per cent from this datum line. Between the first and fourth cardiac output determinations, $3(27 \%)$ of the 11 determinations made were more than 15 per cent from the line of correlation but all were within 25 per cent of this line. In the five subjects in whom five successive determinations of the cardiac output were made, all values fell within 15 per cent of the line of identity, but the number of the latter estimations is small.

These values compare well with those of Korner and Shillingford (1955) who found that three $(21 \%)$ of 14 duplicate determinations of the cardiac output by an identical method fell without 15 per cent but all fell within 25 per cent of the line of identity. Similarly Sekelj et al. (1958) using an ear oximeter method and computor analysis found that $6(23 \%)$ of 26 duplicate determinations were greater than 15 per cent but all were within 20 per cent of the line of identity.

Use of the Dye in Congenital Heart Disease. More than 40 patients suffering from congenital 
TABLE II

Comparison of Successive Cardiac Output Determinations by Dye Oximeter Method

\begin{tabular}{|c|c|c|c|c|c|}
\hline & 1st determination & 2nd determination & 3rd determination & 4th determination & 5 th determination \\
\hline & 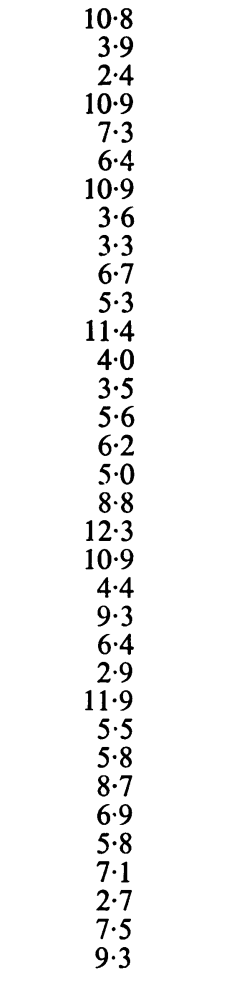 & $\begin{array}{r}12 \cdot 5 \\
4 \cdot 0 \\
2 \cdot 7 \\
9 \cdot 0 \\
7 \cdot 3 \\
8 \cdot 0 \\
8 \cdot 8 \\
3 \cdot 4 \\
3 \cdot 5 \\
5 \cdot 7 \\
5 \cdot 9 \\
10 \cdot 9 \\
5 \cdot 3 \\
4 \cdot 1 \\
4 \cdot 8 \\
6 \cdot 5 \\
5 \cdot 6 \\
7 \cdot 7 \\
10 \cdot 8 \\
10 \cdot 2 \\
5 \cdot 1 \\
8 \cdot 3 \\
7 \cdot 7 \\
2 \cdot 6 \\
11 \cdot 6 \\
6 \cdot 7 \\
4 \cdot 5 \\
8 \cdot 2 \\
7 \cdot 5 \\
6 \cdot 3 \\
6 \cdot 2 \\
2 \cdot 7 \\
8 \cdot 1 \\
8 \cdot 9\end{array}$ & $\begin{array}{r}- \\
- \\
- \\
- \\
- \\
- \\
- \\
- \\
- \\
- \\
- \\
- \\
- \\
- \\
6.8 \\
5.4 \\
7.6 \\
11.0 \\
9.9 \\
5.0 \\
9.6 \\
8.0 \\
2.6 \\
10.4 \\
6.8 \\
4.9 \\
7.0 \\
7.2 \\
5.7 \\
7.3 \\
3.3 \\
8.8 \\
7.9\end{array}$ & 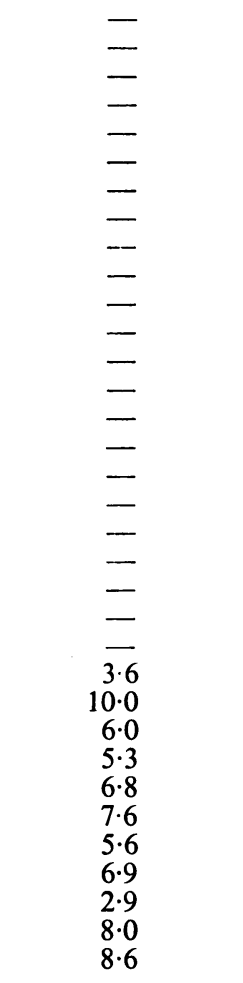 & 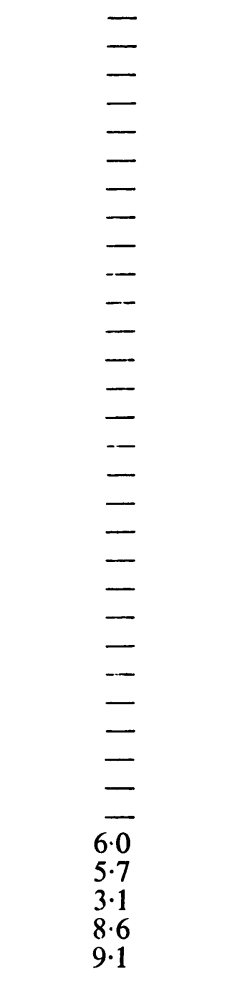 \\
\hline $\begin{array}{l}\text { Mean } \\
\text { S.D. } \\
\text { S.E. of mean }\end{array}$ & $\begin{array}{l}6 \cdot 86 \\
2 \cdot 48 \\
0 \cdot 43\end{array}$ & $\begin{array}{l}6 \cdot 79 \\
2 \cdot 64 \\
0 \cdot 51\end{array}$ & $\begin{array}{l}7 \cdot 12 \\
2 \cdot 28 \\
0 \cdot 48\end{array}$ & $\begin{array}{l}6 \cdot 48 \\
2 \cdot 10 \\
0 \cdot 46\end{array}$ & $\begin{array}{l}6 \cdot 70 \\
2 \cdot 40 \\
0 \cdot 49\end{array}$ \\
\hline
\end{tabular}

TABLE III

Analysis of Variance of Five Successive Determinations of the Cardiac Output in Five Patients by the Dye Oximeter Method

\begin{tabular}{ccc|c|c|c}
\hline & & & D.F. & Sums of Squares & Mean Squares \\
\hline Between patients & $\ldots$ & $\ldots$ & 4 & 10,651 & 2663 \\
\hline Between cardiac outputs & $\ldots$ & 4 & 29 & $7 \cdot 25$ \\
\hline Residual $\quad$. & $\ldots$ & $\ldots$ & 16 & 301 & $18 \cdot 8$ \\
\hline
\end{tabular}

D.F. = Degrees of freedom.

heart disease have been studied by means of selective intracardiac injections of the dye. Injection doses of 40 to $150 \mathrm{mg}$. Coomassie Blue were used in conjunction with a reduced sensitivity of the amplification system of the recorder as described in the methods. A selection of actual dye dilution curves obtained by the ear oximeter method is illustrated in Fig. 3. This study will be presented in more detail elsewhere. 


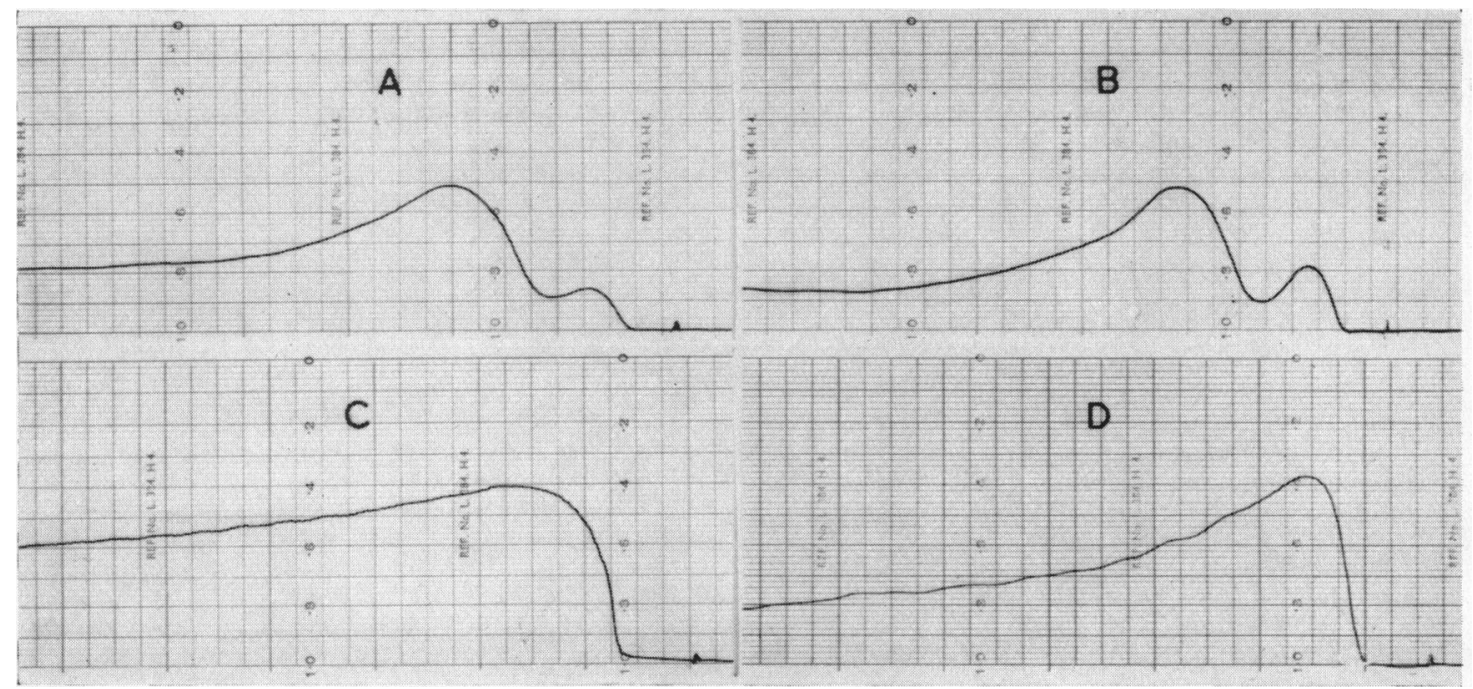

Fig. 3.-Dye curves recorded by the ear oximeter in congenital heart disease; all right atrial injections.

A-Atrial septal defect with right-to-left shunt.

B-Ventricular septal defect with right-to-left shunt.

C-Atrial septal defect with left-to-right shunt.

D-Ventricular septal defect with left-to-right shunt.

\section{Discussion}

The early promise of Coomassie Blue as regards its properties and general biological behaviour has been borne out in clinical practice. Its non-toxicity in animals has been confirmed in man, and its ease of extraction and estimation are noteworthy. The absence of any but transient coloration of the skin has obvious advantages. However, the rate of colorimetric degradation of the dye is not too rapid to preclude the calibration of dye dilution curves for the quantitative estimation of cardiac output by the ear oximeter method. Determinations of the cardiac output by the direct Fick method simultaneously with that by the dye method have been found to agree closely. The repeatability of cardiac output determinations by the dye method has also proved satisfactory. The absence of toxic effects and prolonged skin coloration allow the use of relatively large amounts of the dye both at one time and repeatedly. This character of the dye has been advantageous in its application to the investigation of congenital heart disease. Relatively large doses of the dye, in conjunction with a reduced amplification of the ear oximeter response to overcome fluctuations of the base-line due to changes in oxygen saturation, allow the recording of satisfactory dye dilution curves even in patients with severe cyanosis.

\section{SUMMARY}

Coomassie Blue has been found to be entirely suitable for dye dilution studies in man.

No toxic effects have been observed even after the administration of large intravenous doses of the dye and there is no staining of the skin.

It is easily extracted from plasma and this facilitates the calibration of dye dilution curves. The dye has been found to be suitable for the inscription of dye dilution curves by means of an ear oximeter.

Cardiac output determinations from such curves show close agreement with those obtained simultaneously by the direct Fick method. Repeated determinations of the cardiac output by peripheral venous injections show only a small range of variation.

The combination of large doses of dye and reduced sensitivity of the recording system, to 
overcome base-line instability due to changes in oxygen saturation, makes this dye eminently suitable for the study of congenital heart disease.

The authors are greatly indebted to Professor J. McMichael for his continued help during the preparation of the paper, to Dr. J. F. Goodwin for his co-operation in studies on his patients, and to Dr. K. Cotton for help with the statistical analysis.

The samples of Coomassie Blue were supplied by Imperial Chemical Industries Limited.

\section{REFERENCES}

Davis, H. A., Al-Fadley, W., and Gibson, L. H. (1958). Proc. Soc. exp. Biol., 98, 345.

Doyle, J. T., Wilson, J. S., LePine, C., and Warren, J. V. (1953). J. Lab. clin. Med., 41, 29.

Eliasch, H. (1952). Scand. J. clin. Lab. Invest., 4, Suppl. 4.

Fox, I. J., Brooker, L. G. S., Heseltine, D. W., Essex, H. E., and Wood, E. H. (1957). Proc. Mayo Clin., 32, 463.

Hamilton, W. F., Riley, R. L., Attyah, A. M., Cournand, A., Fowell, D. M., Himmelstein, A., Noble, R. P., Remington, J. W., Richards, D. W., Wheeler, N. C., and Witham, A. C. (1948). Amer. J. Physiol., 153, 309.

Kopelman, H., and Lee, G. de J. (1951). Clin. Sci., 10, 383.

Korner, P. I., and Shillingford, J. P. (1955). Clin. Sci., 15, 417.

Kramer, K., and Ziegenrücker, G. (1957). Klin. Wschr., 35, 468.

Lacy, W. W., Ugaz, C., and Newman, E. V. (1955). Circulat. Res., 3, 570.

Mellette, H., Booth, R. W., Ryan, J. M., and Rieser, G. F. (1958). J. Lab. clin. Med., 51, 441.

Neely, W. A., Wilson, F. C., Milnor, J. P., Hardy, J. D., and Wilson, H. (1954). Surgery, 35, 22.

Ohmori, Kenta, Hirosh Sasamoto and Kiyoshi Hosono (1952). Annual Report, Research Committee on Application of Artificial Radioactive Isotopes in Japan, 2, 141 and 145.

Sekelj, P., Bates, D. V., Johnson, A. L., and Jegier, W. (1958). Amer. Heart J., 55, 810.

Taylor, S. H., and Thorp, J. M. (1959). Brit. Heart J., 21, 492.

Wade, O. L., Bishop, J. M., Cumming, G., and Donald, K. W. (1953). Brit. med. J., 2, 902.

Wassen, A. (1956). Scand. J. clin. Lab. Invest., 8, 189.

Werkö, L., Lagerlöf, H., Bucht, H., Wehle, B., and Holmgren, A. (1949). Scand. J. clin. Lab. Invest, 1, 109.

Wood, E. H., and Geraci, J. E. (1949). J. Lab. clin. Med., 34, 387. 